\title{
Oxytocin prolongs the gastric emptying time in patients with diabetes mellitus and gastroparesis, but does not affect satiety or volume intake in patients with functional dyspepsia
}

Julia Borg and Bodil Ohlsson*

\begin{abstract}
Background: Oxytocin is released in response to a fatty meal. Blockage of the oxytocin receptor led to slower gastric emptying whereas stimulation resulted in less satiety in healthy volunteers. Patients with diabetes mellitus and gastroparesis lack oxytocin elevation, and dyspepsia is partly caused by reduced fundus accommodation causing early satiety and related symptoms. The aim of this study was thus to examine the effect of oxytocin on gastric emptying, satiety and volume intake in patients with gastrointestinal pathology.

Results: Gastric emptying scintigraphy was performed twice in 12 patients with diabetic gastroparesis, once with oxytocin and once with saline as intravenous infusions. The patients scored their sensation of satiety using a visual analogue scale (VAS). The gastric emptying in patients with gastroparesis was prolonged during oxytocin infusion ( $p=0.034$ ) without affecting satiety. A slow satiety drinking test was performed in 14 patients with functional dyspepsia. The patients scored their satiety every five minutes until maximal satiety was reached, and the total volume was determined. The VAS was also completed 30 minutes afterwards. The test was performed twice, once with oxytocin and once with saline as intravenous infusions. There was no difference in satiety scores or volume of nutrient intake between saline and oxytocin infusions, either before, during or after the meal.
\end{abstract}

Conclusions: Oxytocin prolongs gastric emptying in patients with diabetes mellitus and gastroparesis, but has no effect on volume of nutrient intake or satiety and other related symptoms in patients with functional dyspepsia.

Keywords: Diabetes mellitus, Functional dyspepsia, Gastroparesis, Gastric emptying scintigraphy, Slow satiety drinking test

\section{Background}

Oxytocin and its receptor are expressed throughout the gastrointestinal (GI) tract [1,2]. Oxytocin is released in response to a fatty meal in healthy subjects [3], but patients with diabetes mellitus and gastroparesis have been found to lack this response [4]. Furthermore, administration of the oxytocin receptor antagonist atosiban delayed the gastric emptying in healthy subjects [5].

The effect of oxytocin on human gastric emptying has not been entirely established, with some studies showing an accelerated effect after a semisolid meal $[6,7]$ and

\footnotetext{
* Correspondence: bodil.ohlsson@med.lu.se

Department of Clinical Sciences, Division of Gastroenterology, Skåne University Hospital, Malmö, Lund University, Lund, Sweden
}

others showing no effect after a semisolid or solid meal $[5,8]$. In animal trials, studies have shown that oxytocin increases the gastric emptying time and induces satiety due to both central and peripheral effects [9-12]. On the other hand, one animal study has found that oxytocin increases gastric pressure and contracts gastric muscle fibers [13]. This dual effect may be explained by oxytocin exerting its effect both via cholecystokinin (CCK) release and CCK-receptors with subsequent inhibition of gastric emptying $[11,12]$, and via oxytocin receptors stimulating gastric contraction [13].

The pathophysiology of dyspepsia is not yet completely known, but one theory is reduced ventricular accommodation in the fundus leading to various
C Biomed Central

(c) 2012 Ohlsson et al; licensee BioMed Central Ltd. This is an open access article distributed under the terms of the Creative Commons Attribution License (http://creativecommons.org/licenses/by/2.0), which permits unrestricted use, distribution, and reproduction in any medium, provided the original work is properly cited. 
symptoms, e.g. early satiety. A slow drinking satiety test can be used to evaluate the accommodation and any possible pharmacological effects on accommodation and symptoms $[14,15]$. In a previous study in healthy subjects, we found that oxytocin reduced the sensation of satiety without affecting the volume of food intake or gastric emptying [8]. Seeing that functional dyspepsia and gastroparesis are the main clinical syndromes associated with gastric motor dysfunction [15], both of these disorders require further study in relation to oxytocin and its effects.

The aims of this study were to examine the effect of oxytocin 1) on the gastric emptying in patients with diabetes mellitus and gastroparesis, and 2) on satiety and volume intake in patients with functional dyspepsia.

\section{Results}

\section{Gastric emptying test}

The gastric emptying test showed that oxytocin prolonged the gastric emptying significantly compared to saline (Figure 1). Only one patient had longer gastric emptying time during saline than during oxytocin infusions. Although all patients included had verified gastroparesis during the year prior to inclusion, seven had a normal gastric emptying at the time of the saline trial, and three in the oxytocin trial. Three of the patients had normal gastric emptying in both trials.

The fasting blood glucose values revealed no differences between the saline and oxytocin trials (Table 1).
Table 1 Laboratory characteristics of patients with diabetes mellitus and gastroparesis

\begin{tabular}{lc}
\hline Parameter & Value \\
\hline Diabetes duration (years) & $32.0(15.5-39.3)$ \\
$\mathrm{BMI}\left(\mathrm{kg} / \mathrm{m}^{2}\right)$ & $25.8(22.4-30.0)$ \\
$\mathrm{HbA} 1 \mathrm{C}(\mathrm{mmol} / \mathrm{mol})$ & $64.0(59.0-68.8)$ \\
Fasting blood glucose, saline trial $(\mathrm{mmol} \mathrm{L}$ & $-1)$ \\
Fasting blood glucose, oxytocin trial $\left(\mathrm{mmol} \mathrm{L}^{-1}\right)$ & $9.3(7.1-12.2)$ \\
\hline
\end{tabular}

$\mathrm{BMI}=$ body mass index, $\mathrm{HbA} 1 \mathrm{c}=$ glycosylated hemoglobin. Values are given as median (interquartile range).

Also, the visual analogue scale (VAS) scores relative to start value, 30 and 70 minutes after food intake, did not differ between the two trials (Figure 2).

There was a statistically significant negative correlation between age and HbA1c $(r=-0.68 ; p=0.016)$, but no correlation between age and T1/2 for saline or oxytocin infusions ( $p=0.639$ and $p=0.687$, respectively). Neither was there any tendency to correlation between HbA1c and T1/2 for saline or oxytocin infusions $(p=$ 0.989 and $p=0.610$, respectively).

\section{Satiety test}

The satiety test showed no difference in the total volume of nutrient intake between the saline and the oxytocin infusions $(p=0.149)$. The satiety scores before, at maximal satiety and 30 minutes after finishing the meal did not differ between the saline and the oxytocin trials ( $p=0.483, p=0.449$ and $p=0.450$, respectively).

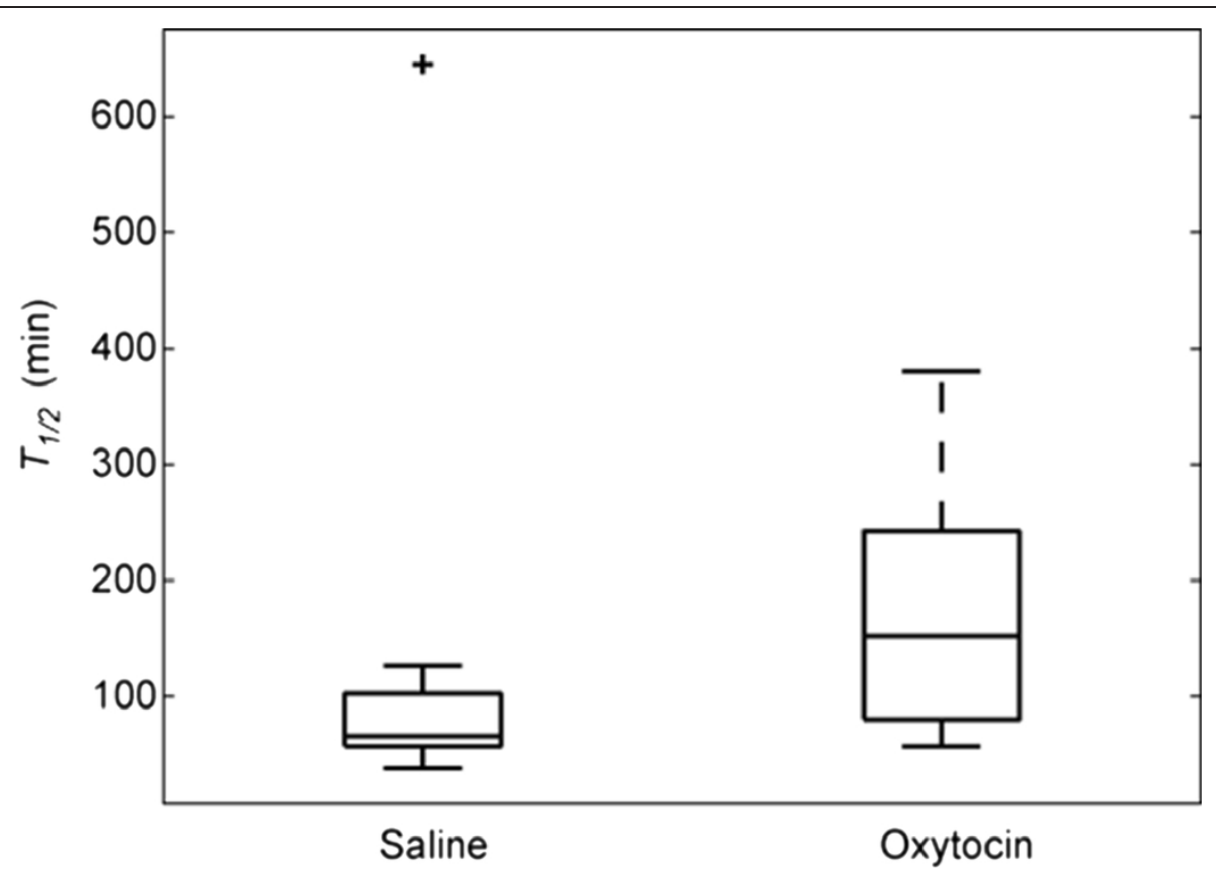

Figure 1 Oxytocin infusions prolonged the gastric emptying time compared to saline in patients with diabetes mellitus and gastroparesis $(\boldsymbol{p}=\mathbf{0 . 0 3 4})$. Values are given as box plots representing median (interquartile range). Wilcoxon's test. 


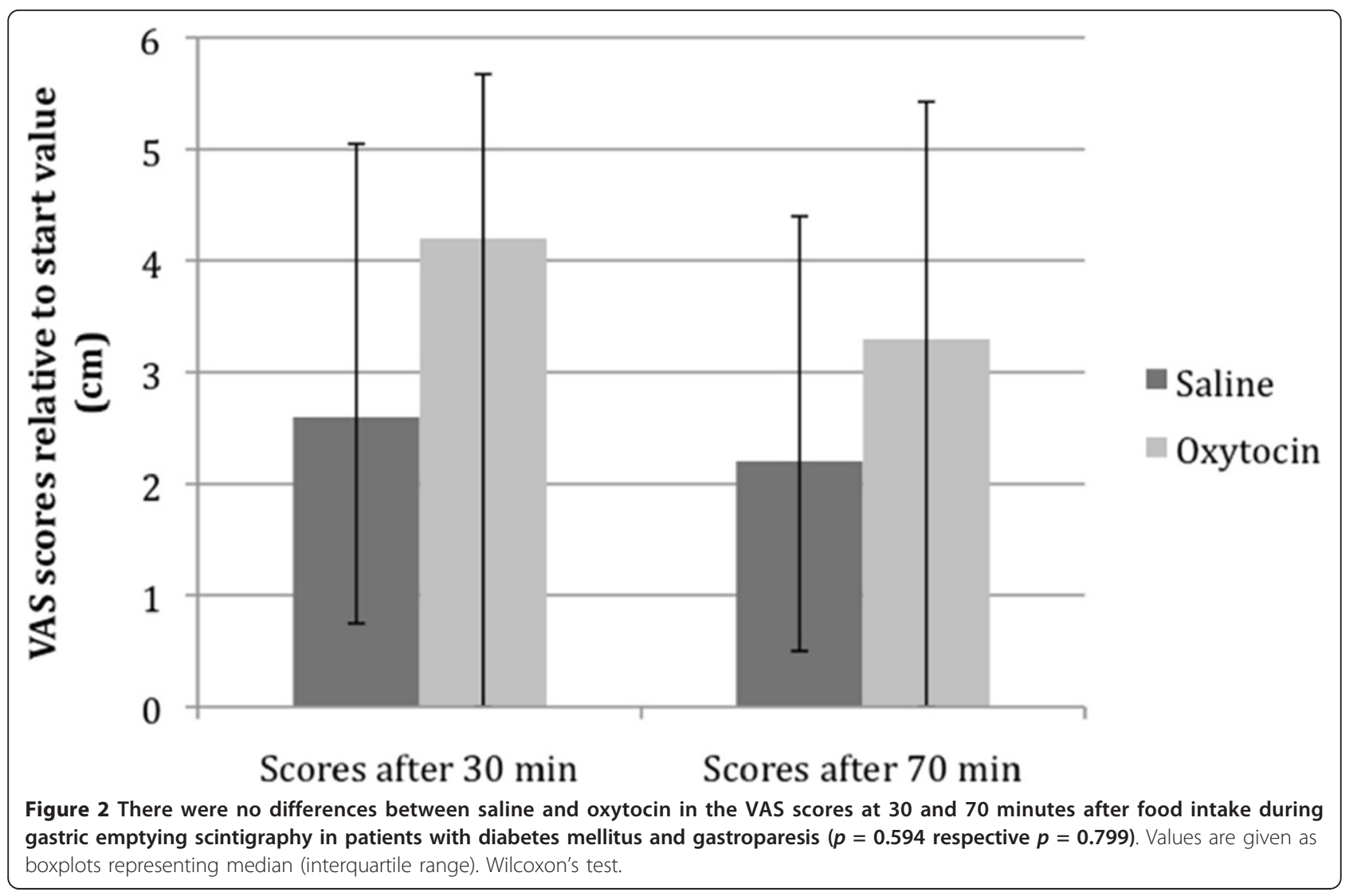

Five patients stopped the test after $40 \mathrm{~min}$. The area under curve (AUC) for the satiety scores up until this time was calculated, and no significant difference was seen (Figure 3; $p=0.953$ ).

The degree of abdominal pain, nausea, abdominal fullness and bloating, registered in the VAS symptoms form 30 minutes after finishing the meal did not differ between the saline and oxytocin infusions $(p=0.735, p$ $=0.374, p=0.674$ and $p=0.735$, respectively).

When dividing the group of patients with functional dyspepsia into those with and those without predominantly early satiety, no differences in volume of nutrient intake, satiety scores before, during and 30 minutes after, nor in the registered symptoms after the test were found (data not shown).

\section{Discussion}

This study showed that oxytocin prolonged the gastric emptying time in patients with diabetes mellitus and gastroparesis, but did not affect the volume of nutrient intake in patients with functional dyspepsia. Oxytocin infusion did not result in lower satiety compared to saline infusion.

Gastroparesis is a disorder in which the gastric emptying is delayed without mechanical obstruction [16]. The pathophysiology is multifactorial, with the following pathologies recognized to date: vagal parasympathetic dysfunction, hyperglycemia, loss of enteric neurons, loss of neuronal nitric oxide expression, smooth muscle abnormalities and disruption of interstitial cells of Cajal networks [17-19].

Previous studies have shown that the oxytocin receptor antagonist atosiban prolonged gastric emptying in healthy subjects [5] and diabetic patients with gastroparesis lacked an elevation of the oxytocin plasma concentration postprandially compared to patients without gastroparesis $[3,4]$. These findings gave rise to the hypothesis that oxytocin may have an essential role in GI motility, especially gastric emptying. However, we could not see any effect of oxytocin on the gastric emptying $[5,8]$. This may be explained by the dual effect oxytocin evokes on normal GI physiology. First, a direct effect of oxytocin on its receptors leads to stimulation of gastric muscle contraction [13]. Secondly, as oxytocin stimulates to CCK release, an indirect action via CCK receptors are activated, leading to inhibition of gastric emptying [11,12]. As atosiban only blocks the oxytocin receptor, delayed gastric emptying was seen during the administration of this specific drug [5].

In the present study, oxytocin prolonged gastric emptying in diabetic gastroparesis. The previously observed lower oxytocin concentration in plasma in patients with 


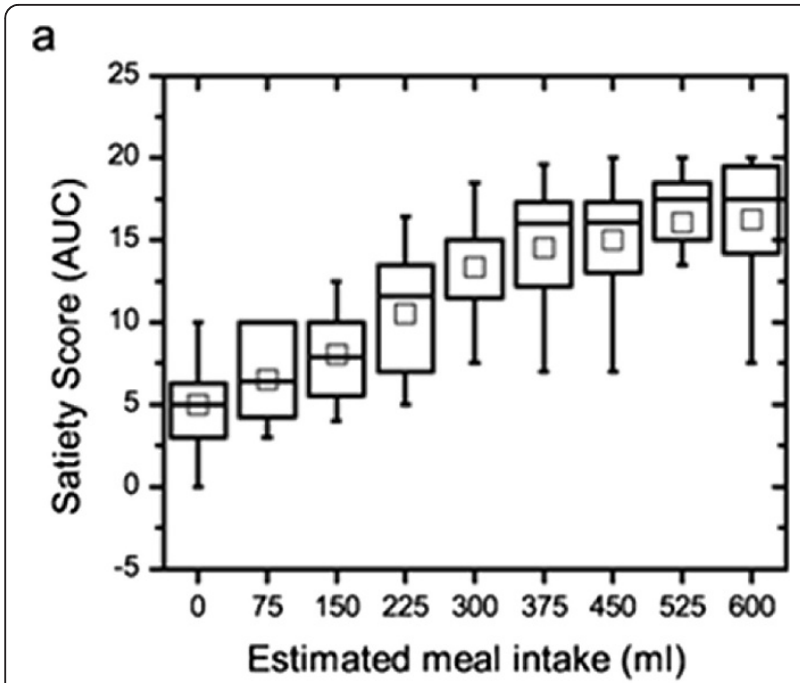

b

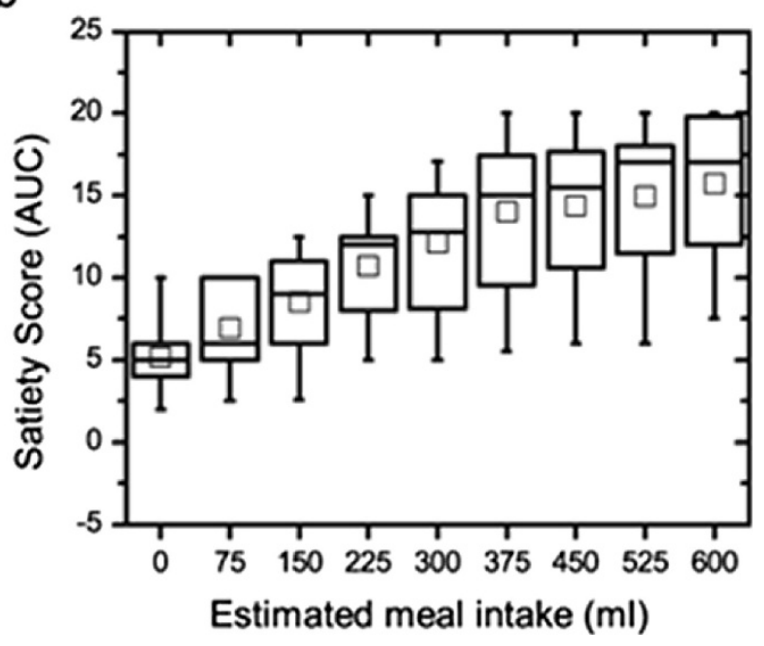

Figure 3 The area under the curve (AUC) for the satiety scores between saline (a) and oxytocin (b) infusions in patients with functional dyspepsia did not differ $(p=0.953)$. Values are given as boxplots representing median (interquartile range). The square inside the boxplot represents mean value. Wilcoxon's test.

gastroparesis must therefore be a secondary, and not a primary etiology of the delayed gastric emptying [4]. It is plausible that the oxytocin receptor pathway is destroyed before the CCK receptor pathway, leading to a loss of contractory stimulation by oxytocin but with a preserved inhibition by the CCK receptors [11-13]. Tension of the gastric wall gives rise to afferent signals to the brain [20]. As oxytocin further delays gastric emptying in a dysfunctional stomach, this may lead to a reduced oxytocin secretion from the hypophysis by a feedback mechanism involving the hypothalamus [21]. Oxytocin exerts both peripheral and central effects on the GI tract as it passes the blood brain barrier [22]. However, the latter pathway is not the primarily by which oxytocin affects gastric motility, which has been found when oxytocin and oxytocin antagonists have been given centrally [23]. It would be interesting to examine the effect of atosiban in gastroparesis, but this drug elevates blood glucose levels and could not be used on patients with diabetes mellitus for ethical reasons.

The effect of the CCK receptor antagonist loxiglumide, which blocks the inhibitory effects on gastric emptying [24], would also be an interesting drug to study in this context. In healthy subjects, an intravenous infusion of loxiglumide stimulated antral contraction and decreased the gastric emptying half time [25]. The $\mathrm{R}$-isomer of loxiglumide, dexloxiglumide, has been tested on patients with functional dyspepsia [26] and functional constipation [27] but not on patients with gastroparesis. In functional dyspepsia, the CCK-receptor antagonist counteracted the increase in gastric volume and dyspeptic symptoms during duodenal lipid infusion, while also reducing gastric compliance [26]. However, the effect on functional constipation has been inconclusive [27].

Oxytocin has in a previous study been shown to be efficient in the treatment of functional abdominal pain and depressed mood [28]. This, together with the described analgesic effect by oxytocin in rats [29], make oytocin analogs to be promising drugs in the future treatment of irritable bowel syndrome (IBS) and depression. The present results of prolongation of gastric emptying by oxytocin underlines the importance of treating IBS patients with oxytocin or its newly developed analogs, first when GI dysmotility has been excluded.

Patients who have symptoms from the upper GI tract in the absence of any organic disease are diagnosed as suffering from functional dyspepsia [30]. Dyspepsia is one of the most common disorders in the GI tract. The findings of cellular pathology in dyspepsia are very sparse, among which a few studies have suggested an increased amount of gastric mast cells, eosinophil degranulation and afferent dysfunction [31,32]. Other studies have shown hypersensitivity in the GI tract to mechanical gastric distension, suggesting enhanced perception of physiological signals [33-35].

Reduced ventricular accommodation after meal intake has been described in $40 \%$ of patients with dyspepsia [36]. According to Tack et al. [37] reduced accommodation is associated with early satiety, making it an important symptom in this subgroup of patients. The slow drinking satiety test has been developed to measure ventricular accommodation to a meal and is therefore particularly suitable for studying this subgroup $[14,15]$.

A previously performed study by our group showed that oxytocin reduces the sensation of satiety without affecting the volume of nutrient intake or gastric emptying in healthy subjects [8]. Thus, it could possibly affect 
early satiety and other symptoms in patients suffering from functional dyspepsia, why we performed the satiety test on these patients. Interestingly, we could not find a difference in satiety, volume intake, abdominal pain, nausea, abdominal fullness and bloating in these patients with oxytocin versus saline. Satiety was not either affected during the gastric emptying test. We have previously described that oxytocin decreases abdominal pain and depression in patients with functional disorders, but has no effect on constipation [28]. Thus, oxytocin seems to have some effects on sensory functions but is not efficient in the treatment of GI dysmotility and symptoms related to the dysmotility. The effect on abdominal pain in IBS may be explained by that the pain experience in IBS, and pain relief of oxytocin, are predominantly central effects $[29,38]$, whereas effects rendering early satiety may predominantly be of peripheral characters $[23,37]$.

One of the limitations of the present study is that although all patients were recently diagnosed as suffering from gastroparesis, some of them had normal gastric emptying in the present study. This may partly be explained by the variation in the GI motility from one day to another [39]. Further, hyperglycemia prolongs gastric emptying [40], and the patients may have been in better metabolic control at the time when they entered in the present study, than at the time of their last gastric emptying scintigraphy. Nevertheless, the patients cannot be considered to have normal gastric function as they have had clinical symptoms of dysfunction leading to admission for gastric scintigraphy, and have once been classified as gastroparetic by the same method. Another limitation is the small sample size, which depends on difficulties to recruite patients in a good metabolic control. The female predominance in the study depends on that these disorders are more common in women than in men $[17,41]$.

\section{Conclusion}

Oxytocin prolongs gastric emptying in patients with diabetes mellitus and gastroparesis, but has no effect on volume of nutrient intake or satiety and other related symptoms in patients with functional dyspepsia.

\section{Methods}

The study has been performed according to the Declaration of Helsinki, and was approved by the Ethics Committee at Lund University and the Swedish Medical Agency (Dnr 2009/502). Written, informed consent was obtained from all participants. All of the subjects completed the tests and no adverse events were reported apart from a few patients suffering from headaches. Trial registration: NCT01152047, NCT00776360.

\section{Subjects}

Patients with diabetes mellitus and gastroparesis, verified by an earlier gastric emptying scintigraphy during the previous year, were invited to undergo gastric emptying scintigraphy on two occasions, one with saline and one with oxytocin infusion, with at least 2 days in between. The patients were recruited from the Department of Endocrinology, Department of Clinical Sciences, Division of Gastroenterology and one primary health care centre in Malmö.

Exclusion criteria were age $<18$ years or $>65$ years and severe complications or cardiac symptoms, which may have entailed possible risks of side effects. Twelve patients (10 women), median age of 56.5 (52.0-64.8) years, in good metabolic control accepted to participate in the study. Glycosylated hemoglobin (HbA1c) was analysed at the Department of Chemistry, Skåne University Hospital, Malmö, according to clinical routines. $\mathrm{HbA}_{1 \mathrm{c}}$ values were collected as Mono-S and subsequently converted to the National Glycohemoglobin Standardization Program (NGSP) standard by use of the following algorithm: $0.923 \times \mathrm{HbA}_{1 \mathrm{c}}($ Mono-S $) \times 1.345=$ $\mathrm{HbA}_{1 \mathrm{c}}$ (NGSP) [42]. Percentage $\mathrm{HbA}_{1 \mathrm{c}}$ values were converted to the International Federation of Clinical Chemistry (IFCC) standard in $\mathrm{mmol} / \mathrm{mol}$ according to the following equation: IFCC $(\mathrm{mmol} / \mathrm{mol})=([\operatorname{NGSP}(\%)]-$ 2,152)/0.09148 [42].

Ten of 12 patients had other diabetic complications aside from gastroparesis, with retinopathy being the most common (Table 2). For further patient characteristics see Tables 1 and 2 .

Patients with functional dyspepsia were invited to perform a slow drinking satiety test on two occasions, one with saline and one with oxytocin infusion. All patients with dyspepsia fulfilled the Rome III criteria for functional dyspepsia [41]. They were recruited by advertisement or from a primary health care centre in Malmö. The most predominant symptoms were registered (Table 3). Exclusion criteria were age $<18$ years or $>65$ years, any other organic GI disorder or other severe diseases. Fourteen patients (12 women), median age of 37.5 (24.0-44.5) years, accepted to participate. None of the patients were using any drugs affecting GI motility.

\section{Visual analogue scale (VAS)}

The patients were asked to complete a questionnaire grading their hunger and/or feeling of satiety, using the VAS satiety scores graded from 0 , for the most extreme hunger, to 20 , for the most extreme satiety $[5,8]$. The VAS scale was labeled with different descriptions of hunger and satiety, from painful hunger to satiety combined with nausea, making it more illustrative. The patients' score at baseline was set to zero, and the values 
measured afterwards were set relative to this point. The scale was used in both the gastric emptying- and the slow drinking satiety test.

\section{Drugs}

The subjects were examined on two different occasions and were given either an infusion of physiological saline or of oxytocin in random order during the experiments. Syntocinon $^{\odot}$ (Novartis, Täby, Sweden), a synthetic ana$\log$ of oxytocin, at a concentration of $8.3 \mu \mathrm{g} \mathrm{mL} \mathrm{L}^{-1}$ was dissolved in $1000 \mathrm{ml}$ saline and given as intravenous infusions for the duration of the experiment. The oxytocin infusion was given at concentrations of 80 and 40 $\mathrm{mU} \mathrm{min}^{-1}$, respectively. These doses were chosen, as they were the most efficient in dose-response trials performed previously in healthy volunteers, and rendered pharmacological plasma concentrations of oxytocin [8]. Both the patients and the staff performing the gastric emptying and satiety tests were unaware of which infusion was being given.

\section{Gastric emptying test}

The patients were studied in the morning after an overnight fast. Patients on regular medication influencing GI motility were asked to stop this treatment two days before the scintigraphy test. Blood glucose was measured before the start of the experiment. If b-glucose was $>18 \mathrm{mml} \mathrm{L}^{-1}$ the experiment was stopped and the patient was sent home. When b-glucose was $>12 \mathrm{mmol}$ $\mathrm{L}^{-1}$, the patients were given half of their ordinary insulin dosage at the laboratory before the start of the experiment.

A test meal was prepared by adding tin colloid labeled with 30-50 Mbq of $99 \mathrm{~m}_{\mathrm{Tc}}$ to an egg, which was whipped in a glass cup in a hot water bath until coagulated. The egg and a slice of toasted white bread were

Table 2 Clinical characteristics of patients with diabetes mellitus and gastroparesis $(n=12)$

\begin{tabular}{ll}
\hline & No (\%) \\
\hline Diabetes mellitus type 1 & $9(75)$ \\
Diabetes mellitus type 2 & $3(25)$ \\
Women & $10(83)$ \\
Men & $2(17)$ \\
Other complications of diabetes mellitus & $10(83)$ \\
$\quad$ - Retinopathy & $8(67)$ \\
$\quad$ Peripheral neuropathy & $7(58)$ \\
$\quad$ - Nephropathy & $2(17)$ \\
Pharmacological treatment for gastrointestinal dysmotility & $7(58)$ \\
Insulin treatment & $4(33)$ \\
Oral hypoglycemic drugs & $10(83)$ \\
Hypothyroidism & $3(25)$ \\
\hline
\end{tabular}

Table 3 Clinical characteristics of patients with functional dyspepsia $(n=14)$

\begin{tabular}{ll}
\hline & No (\%) \\
\hline Women & $12(86)$ \\
Ben & $2(14)$ \\
Early satiety as predominant symptom/symptoms & $5(36)$ \\
Epigastric pain as predominant symptom/symptoms & $6(43)$ \\
Epigastric burning as predominant symptom/symptoms & $2(14)$ \\
\hline
\end{tabular}

cut into pieces smaller than $1 \times 1 \mathrm{~cm}$ and served with $100 \mathrm{ml} 37^{\circ} \mathrm{C}$ water. The meal was eaten within five minutes. Immediately thereafter a large-field double-headed gamma camera (Philips Skylight, Philips Medical Systems, Best, The Netherlands) was placed anteriorly and posteriorly parallel to the upper abdominal wall. The radioactivity was measured continuously (1-min frames) for 70 minutes starting immediately after meal ingestion. A Region of Interest (ROI) representing the stomach was created and the activity of the first frame was taken as $100 \%$. The gradual decreasing radioactivity, measured as the number of radioactivity decays per minute (counts/min), was plotted against time. The time elapsed to reach a $50 \%$ decrease of the activity in the ROI (T1/ 2) was identified as the point at which this plot crossed the $50 \%$ value. The values of the radioactivity measured were corrected for the half-life of ${ }^{99} \mathrm{~m}$ Tc, and for attenuation by using the geometrical mean values of the decay curves obtained from the two gamma camera heads used. T1/2 > 2 standard deviations (SD) for healthy control subjects (70 $\mathrm{min})$ was considered abnormal [43].

An infusion of either saline or $80 \mathrm{mU}$ oxytocin $\mathrm{min}^{-1}$ was started at the same time as the meal intake began, and was given throughout the experiments. The subjects also scored their satiety using a VAS score, at time 0 when the meal intake began, and 30 and 70 minutes after the meal intake. The gastric emptying time and VAS scores were used for statistical calculations.

\section{Satiety test}

The satiety test was performed according to a previously developed protocol by Tack et al. [14], using a slightly modified VAS scale which has been used in other studies performed by our group $[5,8]$. The patients were studied in the morning after an overnight fast. A peristaltic pump filled one of two beakers at a rate of $15 \mathrm{ml}$ $\min ^{-1}$ with a liquid meal consisting of $13 \%$ protein, $48 \%$ carbohydrate and $39 \%$ lipids $\left(\right.$ Nutridrink $^{\odot}$; Nutricia, Bornem, Belgium), giving $1.5 \mathrm{kcal} \mathrm{ml}^{-1}$. The patients were requested to maintain their intake at the filling rate, alternating the beakers as they were filled and emptied. The participants were instructed to terminate their meal 
when maximum satiety was reached and they could not continue to drink any more. At the start of the experiment and at five-minute intervals, they recorded their satiety using the VAS until they terminated their meal. A further VAS score for satiety and a separate VAS to score other GI symptoms, namely, abdominal pain, nausea, abdominal fullness and bloating, were completed 30 minutes after the end of the meal. An infusion of saline or $40 \mathrm{mU}$ oxytocin $\mathrm{min}^{-1}$ was started at the same time as the meal intake began and was terminated when the meal was ended. The volume of nutrient intake and registered VAS scores were used in the statistical calculations.

\section{Statistical analyses}

Values are given as median (interquartile range, IQR). The VAS scores relative to baseline and AUC for VAS scores were calculated. Statistic differences in gastric emptying time and related VAS scores in the gastric emptying test and differences in satiety scores, AUC for VAS, volume of nutrient intake and VAS scores for GI symptoms in the satiety test were determined using Wilcoxon's test. Correlations were determined using Spearman's test. $\mathrm{P}<0.05$ was considered statistically significant.

\section{Abbreviations}

AUC: Area under the curve; CCK: Cholecystokinin; Gl: Gastrointestinal; HbA1C: Glycosylated hemoglobin; IBS: Irritable bowel syndrome; IFCC: International federation of clinical chemistry; NGSP: National glycohemoglobin standardization program; ROI: Region of Interest; SD: Standard deviation; T1/ 2: Time elapsed to reach a $50 \%$ decrease of the activity in the ROI; VAS: Visual analogue scale.

\section{Acknowledgements}

This study was supported by grants from the Development Foundation of Region Skane, the Crafoord Foundation and the Bengt Ihre Foundation. We want to thank the staff at the Department of Nuclear Medicine, Diagnostic Centre of Imaging and Functional Medicine, and at the Internal Medicine Research Group, Skåne University Hospital, Malmö for performing the trials. We also thank Mikael Truedsson, M.D., for helping to recruit patients with functional dyspepsia to the study.

\section{Authors' contributions}

Both authors designed the research study. BO contributed to essential reagents and tools. JB analyzed the data and wrote the paper. $\mathrm{BO}$ contributed to the manuscript with constructive criticism, and read and approved the final manuscript. All authors read and approved the final manuscript.

\section{Competing interests}

The authors declare that they have no competing interests.

Received: 1 December 2011 Accepted: 16 March 2012

Published: 16 March 2012

\section{References}

1. Monstein HJ, Grahn N, Truedsson M, Ohlsson B: Oxytocin and oxytocinreceptor mRNA expression in the human gastrointestinal tract: a polymerase chain reaction study. Regul Pept 2004, 119:39-44.

2. Ohlsson B, Truedsson M, Djerf $P$, Sundler F: Oxytocin is expressed throughout the human gastrointestinal tract. Regul Pept 2006, 135:7-11.
3. Ohlsson B, Forsling ML, Rehfeld JF, Sjolund K: Cholecystokinin stimulation leads to increased oxytocin secretion in women. Eur J Surg 2002, 168:114-118.

4. Borg J, Melander O, Johansson L, Uvnas-Moberg K, Rehfeld JF, Ohlsson B: Gastroparesis is associated with oxytocin deficiency, oesophageal dysmotility with hyperCCKemia, and autonomic neuropathy with hypergastrinemia. BMC Gastroenterol 2009, 9:17.

5. Ohlsson B, Bjorgell O, Ekberg O, Darwiche G: The oxytocin/vasopressin receptor antagonist atosiban delays the gastric emptying of a semisolid meal compared to saline in human. BMC Gastroenterol 2006, 6:11.

6. Hashmonai M, Torem S, Argov S, Barzilai A, Schramek A: Prolonged postvagotomy gastric atony treated by oxytocin. Br J Surg 1979, 66:550-551.

7. Petring OU: The effect of oxytocin on basal and pethidine-induced delayed gastric emptying. Br J Clin Pharmacol 1989, 28:329-332.

8. Borg J, Simren M, Ohlsson B: Oxytocin reduces satiety scores without affecting the volume of nutrient intake or gastric emptying rate in healthy subjects. Neurogastroenterol Motil 2011, 23:56-61.

9. McCann MJ, Verbalis JG, Stricker EM: LiCl and CCK inhibit gastric emptying and feeding and stimulate OT secretion in rats. Am J Physiol 1989, 256: R463-R468.

10. Verbalis JG, McCann MJ, McHale CM, Stricker EM: Oxytocin secretion in response to cholecystokinin and food: differentiation of nausea from satiety. Science 1986, 232:1417-1419.

11. Wu CL, Hung CR, Chang FY, Pau KY, Wang JL, Wang PS: Involvement of cholecystokinin receptor in the inhibition of gastric emptying by oxytocin in male rats. Pflugers Arch 2002, 445:187-193.

12. Wu CL, Hung CR, Chang FY, Pau KY, Wang PS: Pharmacological effects of oxytocin on gastric emptying and intestinal transit of a non-nutritive liquid meal in female rats. Naunyn Schmiedebergs Arch Pharmacol 2003, 367:406-413.

13. Qin J, Feng $M$, Wang $C$, Ye $Y$, Wang PS, Liu C: Oxytocin receptor expressed on the smooth muscle mediates the excitatory effect of oxytocin on gastric motility in rats. Neurogastroenterol Motil 2009, 21:430-438.

14. Tack J, Caenepeel P, Piessevaux H, Cuomo R, Janssens J: Assessment of meal induced gastric accommodation by a satiety drinking test in health and in severe functional dyspepsia. Gut 2003, 52:1271-1277.

15. Tack J: Prokinetics and fundic relaxants in upper functional GI disorders. Curr Opin Pharmacol 2008, 8:690-696.

16. Parkman HP, Hasler WL, Fisher RS, American Gastroenterological Association: American Gastroenterological Association technical review on the diagnosis and treatment of gastroparesis. Gastroenterology 2004 127:1592-1622.

17. Faraj J, Melander O, Sundkvist G, Olsson R, Thorsson O, Ekberg O, Ohlsson B: Oesophageal dysmotility, delayed gastric emptying and gastrointestinal symptoms in patients with diabetes mellitus. Diabet Med 2007, 24:1235-1239.

18. Kong MF, Horowitz M: Diabetic gastroparesis. Diabet Med 2005, 22(Suppl 4):13-18

19. Parkman HP, Camilleri M, Farrugia G, McCallum RW, Bharucha AE, Mayer EA, Tack JF, Spiller R, Horowitz M, Vinik Al, Galligan JJ, Pasricha PJ, Kuo B, Szarka LA, Marciani L, Jones K, Parrish CR, Sandroni P, Abell T, Ordog T, Hasler W, Koch KL, Sanders K, Norton NJ, Hamilton F: Gastroparesis and functional dyspepsia: excerpts from the AGA/ANMS meeting Neurogastroenterol Motil 2010, 22:113-133.

20. Shapiro RE, Miselis RR: The central organization of the vagus nerve innervating the stomach of the rat. J Comp Neurol 1985, 238:473-488.

21. Ueta $Y$, Kannan $H$, Yamashita H: Gastric afferents to the paraventricular nucleus in the rat. Exp Brain Res 1991, 84:487-494.

22. Ermisch A, Barth T, Ruhle HJ, Skopkova J, Hrbas P, Landgraf R: On the blood-brain barrier to peptides: accumulation of labelled vasopressin DesGlyNH2-vasopressin and oxytocin by brain regions. Endocrinol Exp 1985, 19:29-37.

23. Flanagan LM, Olson BR, Sved AF, Verbalis JG, Stricker EM: Gastric motility in conscious rats given oxytocin and an oxytocin antagonist centrally. Brain Res 1992, 578:256-260

24. Galligan JJ, Vanner S: Basic and clinical pharmacology of new motility promoting agents. Neurogastroenterol Motil 2005, 17:643-653.

25. Schwizer W, Borovicka J, Kunz P, Fraser R, Kreiss C, D'Amato M, Crelier G, Boesiger $\mathrm{P}$, Fried M: Role of cholecystokinin in the regulation of liquid gastric emptying and gastric motility in humans: studies with the CCK antagonist loxiglumide. Gut 1997, 41:500-504 
26. Feinle C, Meier O, Otto B, D'Amato M, Fried M: Role of duodenal lipid and cholecystokinin A receptors in the pathophysiology of functional dyspepsia. Gut 2001, 48:347-355.

27. D'Amato W, Thompson DG, Spiller RC, Giacovelli G, Griffin PH, Schneier H, Lucio RC: The CCK1 receptor antagonist dexloxiglumide is effective and safe in female patients with constipation predominant irritable bowel syndrome. Am J Gastroenterol 2001, 96:S317.

28. Ohlsson B, Truedsson M, Bengtsson M, Torstenson R, Sjölund K, Björnsson ES, Simrèn M: Effects of long-term treatment with oxytocin in chronic constipation; a double blind, placebo-controlled pilot trial. Neurogastroenterol Motil 2005, 17:697-704

29. Petersson M, Alster $P$, Lundeberg $T$, Uvnas-Moberg K: Oxytocin increases nociceptive thresholds in a long-term perspective in female and male rats. Neurosci Lett 1996, 212:87-90

30. Tack J, Talley NJ, Camilleri M, Holtmann G, Hu P, Malagelada JR, Stanghellini V: Functional gastroduodenal disorders. Gastroenterology 2006, 130:1466-1479.

31. Talley NJ, Walker MM, Aro P, Ronkainen J, Storskrubb T, Hindley LA, Harmsen WS, Zinsmeister AR, Agréus L: Non-ulcer dyspepsia and duodenal eosinophilia: an adult endoscopic population-based casecontrol study. Clin Gastroenterol Hepatol 2007, 5:1175-1183.

32. Friesen CA, Lin Z, Singh M, Singh V, Schurman JV, Burchell N, Cocjin JT, McCallum RW: Antral inflammatory cells, gastric emptying, and electrogastrography in pediatric functional dyspepsia. Dig Dis Sci 2008, 53:2634-2640.

33. Karamanolis G, Caenepeel P, Arts J, Tack J: Association of the predominant symptom with clinical characteristics and pathophysiological mechanisms in functional dyspepsia. Gastroenterology 2006, 130:296-303.

34. Azpiroz F, Bouin M, Camilleri M, Mayer EA, Poitras P, Serra J, Spiller RC Mechanisms of hypersensitivity in IBS and functional disorders. Neurogastroenterol Motil 2007, 19:62-88.

35. Camilleri M: Functional dyspepsia: mechanisms of symptom generation and appropriate management of patients. Gastroenterol Clin North Am 2007, 36:649-664.

36. Talley NJ, Choung RS: Whither dyspepsia? A historical perspective of functional dyspepsia, and concepts of pathogenesis and therapy in 2009. J Gastroenterol Hepatol 2009, 24(Suppl 3):20-28.

37. Tack J, Piessevaux H, Coulie B, Caenepeel P, Janssens J: Role of impaired gastric accommodation to a meal in functional dyspepsia. Gastroenterology 1998, 115:1346-1352.

38. Elsenbruch S, Rosenberger C, Enck P, Forsting M, Schedlowski M, Gizewski ER: Affective disturbances modulate the neural processing of visceral pain stimuli in irritable bowel syndrome: an fMRI study. Gut 2010, 59:489-495.

39. Beckers EJ, Rehrer NJ, Saris WH, Brouns F, Ten Hoor F, Kester AD: Daily variation in gastric emptying when using the double sampling technique. Med Sci Sports Exerc 1991, 23:1210-1212.

40. Horowitz M, O'Donovan D, Jones KL, Feinle C, Rayner CK, Samsom M: Gastric emptying in diabetes: clinical significance and treatment. Diabet Med 2002, 19:177-194.

41. Drossman DA: The functional gastrointestinal disorders and the Rome III process. Gastroenterology 2006, 130:1377-1390.

42. Hoelzel W, Weykamp C, Jeppsson JO, Miedema K, Barr JR, Goodall I, Hoshino T, John WG, Kobold U, Little R, Mosca A, Mauri P, Paroni R, Susanto F, Takei I, Thienpont L, Umemoto M, Wiedmeyer H-M, the IFCC working group on $\mathrm{HbA1C}$ standardization: IFCC reference system for measurement of hemoglobin A1c in human blood and the national standardization schemes in the United States, Japan, and Sweden: a method-comparison study. Clin Chem 2004, 50:166-174.

43. Hanson M, Lilja B: Gastric emptying in smokers. Scand J Gastroenterol 1987, 22:1102-1104.

doi:10.1186/1756-0500-5-148

Cite this article as: Borg and Ohlsson: Oxytocin prolongs the gastric emptying time in patients with diabetes mellitus and gastroparesis, but does not affect satiety or volume intake in patients with functional dyspepsia. BMC Research Notes 2012 5:148.

\section{Submit your next manuscript to BioMed Central and take full advantage of:}

- Convenient online submission

- Thorough peer review

- No space constraints or color figure charges

- Immediate publication on acceptance

- Inclusion in PubMed, CAS, Scopus and Google Scholar

- Research which is freely available for redistribution

Submit your manuscript at www.biomedcentral.com/submit
Biomed Central 